ESCRITAS Vol. 9 n. 1 (2017) ISSN 2238-7188 p. 160-182

\title{
HISTÓRIA DA IMPRENSA E JORNALISMO AGRONÔMICO: POSSIBILIDADES DE PESQUISA
}

\section{HISTORY OF THE PRESS AND AGRONOMICAL JOURNALISM: POSSIBILITIES OF RESEARCH}

Eduardo de Melo Salgueiro ${ }^{1}$

\begin{abstract}
RESUMO: Este trabalho pretende discutir o potencial de pesquisa encontrado na chamada imprensa agronômica. Para tanto, pretendo evidenciar como este segmento editorial pode contribuir para os estudos históricos, uma vez que historicamente há um grande número de publicações - especialmente revistas - que discutem questões nacionais e o" mundo do campo" no interior de suas páginas. Esta preocupação surgiu quando empreendi pesquisas que se depararam com as chamadas revistas rurais. O mais surpreendente, no entanto, foi perceber que há grande lacuna no interior da historiografia brasileira quando se pensa esta modalidade de impresso periódico pensado como fonte e objeto de pesquisa. Assim, pretendo abordar tal questão, apresentar uma síntese da história da imprensa rural, bem como indicar possibilidades de pesquisas a partir de minhas próprias experiências.
\end{abstract}

PALAVRAS-CHAVE: Imprensa; História; Historiografia; Pesquisa; Ruralismo.

\begin{abstract}
This article discusses the potential research found on the agronomical press. Therefore, I intend to show how this editorial segment can be useful to the historical studies, since historically there are many publications - especially magazines - discussing national and "rural world" issues within its pages. This concern arose when I did some researches about rural magazines. Most surprising, however, it was the realization that there is big gap inside the Brazilian historiography when you think this type of periodical thought as a source and object of research. So, I want to address this question, provide a summary of the history of the rural press and indicate possibilities of researches through my own experiences.
\end{abstract}

KEYWORDS: Press; History; Historiography; Research; Rurality.

\footnotetext{
${ }^{1}$ Doutor em História. Professor do Instituto de Estudos do Trópico Úmido, Departamento de História. Universidade Federal do Sul e Sudeste do Pará (Unifesspa).
} 
INTRODUÇÃO

Este artigo tem como objetivo principal fazer uma discussão a respeito da chamada "imprensa agronômica", isto é, periódicos que, de modo geral, dedicam especial atenção aos assuntos ligados à pecuária e agricultura. ${ }^{2}$ Tal preocupação surgiu quando, em minhas pesquisas de mestrado e doutorado, trabalhei com periódicos que tinham como foco principal, publicar reportagens e artigos que debatessem especialmente assuntos do mundo agropecuário.

A publicação que tenho analisado mais sistematicamente tem sido a revista Brasil-Oeste $^{3}$, mensário paulista que circulou entre os anos 1956 e 1967 e que se enquadra no interior do chamado segmento agronômico. Contudo, neste texto não tenho como principal objetivo abordá-la especificamente, pois minha preocupação é outra, qual seja, chamar atenção para o periodismo rural (sobretudo a publicação revisteira) que, como se verá mais adiante, carece de maior atenção por parte de nossa historiografia. De todo modo, quando for necessário, irei me remeter ao supramencionado magazine.

\section{IMPRENSA AGRONÔMICA E HISTORIOGRAFIA BRASILEIRA}

Apesar de toda a importância do segmento editorial agronômico no desenvolvimento do jornalismo nacional, bem como os visíveis avanços na historiografia brasileira, há uma notável ausência nos estudos sobre a história da imprensa em relação à segmentação agrícola. Além disso, é válido dizer que boa parte dos que existem foram feitos em outros campos disciplinares, tais como a História das Ciências, Geografia ou Ciências da Saúde, por exemplo.

Dentre os trabalhos específicos da área de História que pude encontrar, é importante citar o mais antigo de que tenho conhecimento, qual seja, a produção sobre

\footnotetext{
${ }^{2}$ Boa parte dos estudos que serão apresentados aqui, ora conceituam esta segmentação editorial como "imprensa agronômica", ora como "imprensa agrícola", ou até mesmo como "imprensa rural". Logo, optarei por usar todas essas nomenclaturas levando em consideração que minha preocupação aqui está mais ligada a estudos que se dedicaram a analisar periódicos preocupados com questões relacionadas à chamada grande agropecuária, a partir de uma perspectiva que visava seu desenvolvimento científico, tecnológico e econômico.

${ }^{3}$ De modo resumido, pode-se dizer que sua linha editorial se dedicava a difundir reportagens e artigos que abrangessem o mundo dos negócios agropastoris, direcionando seu olhar para a região oeste do Brasil (especialmente o estado de Mato Grosso), por meio de anúncios e informações sobre a política e economia. Circulou entre os anos de 1956 e 1967, totalizando a produção de 123 edições com dimensões de 27x18,5cm. A tiragem máxima da revista atingiu a quantia de 18.500 exemplares no ano de 1967 , totalizando cerca de 1.500 .000 deles durante os anos em que esteve em circulação. No que diz respeito à distribuição, a editora o fazia de três maneiras: vendas avulsas, assinaturas e distribuição gratuita para associações rurais e órgãos públicos.
} 
história da imprensa no Brasil escrita por Hélio Viana (1945), na qual o autor dedica um capítulo especial ao jornalismo agronômico. Não se trata, portanto, de uma pesquisa especialmente dedicada ao segmento em tela, mas é válido seu esforço, uma vez que soube perceber a importância do mesmo no interior da produção jornalística brasileira.

A historiadora Ana Luiza Martins também desenvolveu pesquisas nessa área, pois em seu clássico estudo sobre a imprensa revisteira, dedicou um capítulo sob o título "No país rural, revistas agronômicas". Além disso, também publicou um artigo analisando especificamente a importante revista Chácaras e Quintais (MARTINS, 2001; MARTINS, 2004).

Amilson B. Henriques fez salutar pesquisa em sua dissertação de mestrado, na qual se preocupou em analisar a Revista Agrícola no período correspondente a 1895-1907. Seu intuito foi perceber os discursos presentes naquele periódico sobre a modernização da agricultura brasileira (HENRIQUES, 2010). O grifo em itálico pretende indicar uma das mais fecundas possibilidades de pesquisa quando nos deparamos com revistas agronômicas, qual seja, a "ideia” ou o "ideal” de modernização.

Outra pesquisa de fôlego publicada em 2014 em formato de tese, foi o trabalho empreendido pela historiadora Evelyn Morgan Monteiro que, a partir de três periódicos principais, buscou identificar como o "mundo do campo" foi "interpretado" por intelectuais fluminenses nos anos 1920 (PAIVA, 2014). Ademais, também tive a oportunidade de desenvolver dois projetos que trataram de elencar como objeto principal de pesquisa uma revista agronômica (Brasil-Oeste), publicados em formato de dissertação e tese (SALGUEIRO, 2011; 2016).

Outros dois trabalhos foram feitos por pesquisadores graduados em História, mas com pós-graduação na área de Ensino e História de Ciências da Terra, tais como foram os casos de Begonha Eliza H. Bediaga (2013) e Mário Roberto Ferraro (2015) que, assim como o Amilson Henriques, também se dedicaram a estudar a Revista Agrícola.

Nota-se que na maior parte das pesquisas supramencionadas, há especial atenção para o período que corresponde o final do século XIX e início do XX. O mesmo vale para alguns trabalhos que pude encontrar e que foram feitos por pesquisadores e pesquisadoras de outras áreas (ANTUNIASSI; BARZOTTO, 1997; MORAES, 2005; SANTOS, 2012; SOUZA, 2010; TEMPERINI, 2003; WELTMAN, 2008). Neste sentido, além de ser baixo o número de pesquisas que tratam de discutir a imprensa agronômica no âmbito do campo da 
História, ${ }^{4}$ é notória a falta de produção historiográfica sobre periódicos publicados em períodos mais recentes.

Alguns dos trabalhos acima arrolados trataram de fazer abordagens mais específicas a partir de periódicos tratados ora como fontes, ora como objetos de pesquisa. De todo modo, acredito que exista outra relevante referência (embora com objetivo um pouco diferente) que se torna imprescindível para os historiadores da imprensa agronômica. Trata-se do trabalho desenvolvido por João Castanho Dias (2011), jornalista que dedicou uma obra especialmente para falar sobre a história evolução desse segmento editorial no Brasil. Deste modo, como vimos, ainda que possa haver ausências nos resultados de minhas buscas, há muito para ser explorado em termos de imprensa agronômica.

Nas pesquisas com as quais tive contato, pude perceber que houve preocupação por parte de boa parte dos autores em relação aos chamados "projetos de desenvolvimento" pensados regional e nacionalmente, bem como a já mencionada "modernização do campo". Como mostrarei mais adiante, nota-se que apesar da especificidade do periodismo em tela, isto é, ser um tipo de publicação "técnica” que pretende atingir um público restrito, percebe-se que existe efetivamente um discurso de fundo que tem total ligação com os aspectos acima mencionados. Neste sentido, a seguir apresento um breve histórico sobre o desenvolvimento desse segmento editorial e o potencial de pesquisa existente nele.

\section{HISTÓRIA E IMPRENSA: REVISTAS AGRONÔMICAS}

Quando falamos em pesquisa em revistas, logo nos remetemos aos estudos de Ana Luiza Martins, autora de colossal estudo sobre a imprensa revisteira no período da chamada Primeira República do Brasil. Neste sentido, é válido lembrar aquilo que é informado por ela quando afirma que, desde o fim do século XIX, as revistas já se dedicavam à função "de suporte adequado para a veiculação da imagem de um novo Brasil", uma vez que traduziam as “conquistas técnicas com as quais a imprensa periódica se defrontava, construída a serviço de um ideário inovador e não raro também a serviço da defesa das tradições” (MARTINS, 2008, p. 26-27, os grifos são meus). Em outro estudo, Martins e Tania Regina de Luca afirmam que na Primeira República, as revistas eram um gênero privilegiado em relação aos jornais, "pela melhor resolução gráfica dos então ultramodernos recursos visuais recém-apropriados como a zincografia e a fotografia" (LUCA; MARTINS, 2006, p. 39). No mesmo sentido, André de

\footnotetext{
${ }^{4}$ É preciso dizer que possivelmente existem ausências nos dados que levantei, no entanto, as buscas que fiz levaram em consideração o banco de dados da CAPES, revistas especializadas e programas de pós-graduação.
} 
Seguin des Hons acredita que os magazines agiram mais rapidamente frente às mudanças culturais. Em suas palavras,

Les magazines sont un élément significatif dans l'histoire de la culture brésilienne. Il semble que, à l'instar de la presse internationale, les magazines brésiliens aient encore été plus sensibles aux changements de mentalités et aux mouvements culturels que les quotidiens (1985, p. 25).

Nesse sentido, o ascendente mercado de revistas do crepúsculo do século XIX e aurora do XX (1890-1922), ampliava-se consideravelmente, bem como crescia a oferta e a variedade da segmentação editorial na imprensa revisteira. Assim, dentre as várias opções que se apresentavam, era significativa a presença das agronômicas (MARTINS, 2003) que emergiam no interior de um dos segmentos com maior projeção.

O que explica a ascensão do periodismo agronômico? Conforme informa Martins, no final do século XIX houve uma crise no setor cafeeiro que acabou por desencadear a "baixa cotação internacional do produto, desarticulando fortunas, propriedades e trabalhadores do campo". Ainda nas palavras da autora, o "lavrador brasileiro lidava com técnicas primitivas do amanho do solo e cultivo dos produtos da terra" e "mesmo o cafeicultor paulista, tido como inovador na mecanização agrícola, mostrava-se refratário a aplicações econômicas que qualificassem e potencializassem seus negócios” (2001, p. 282). Esse homem do campo (especialmente o fazendeiro paulista) viu-se obrigado a buscar mais informações de mercado e essa "necessidade [...] justificava o investimento no periodismo agrícola". Assim, exigiu-se "um proprietário mais informado e atento, capaz de gerenciar mão de obra competitiva, vendas diretas de café aos escritórios estrangeiros, mecanismos para fornecimento de crédito, otimização da produção" (2001, p. 283-284).

Em decorrência, o gênero agronômico - inicialmente modesto -, com características de folhetos e boletins, ganhou fôlego e cresceu na ordem de títulos $47,8 \%$ entre os anos de 1912-1930. Joao Castanho Dias (2011), por sua vez, traz um quadro no qual apresenta todas as publicações agronômicas existentes no país entre 1832 e 1921, a partir do que coletou junto ao "Annuario Commercial Industrial e Agrícola" (1924), lançado pelo Instituto Agrícola Brasileiro. Foram 115 periódicos arrolados pelo autor publicados nas mais diversas regiões do país, com predominância na região Sudeste (60), seguida de Nordeste (24), Sul (17), Norte (6) e Centro-Oeste (1). Os demais não possuíam informação de procedência regional.

Este considerável incremento no interior do segmento agronômico pode ser explicado, segundo Martins, especialmente porque 
para investimentos, contemplando de anúncios de implementos agrícolas à necessária orientação técnica sobre produtos do campo (2003, p. 67).

Deste modo, cumpre destacar que, desde os fins do século XIX e início do XX, as revistas agronômicas tinham como principal característica fazer de suas páginas um canal de propaganda e defesa dos fazendeiros produtores de café, como destacou Martins em relação à revista $O$ Fazendeiro, ${ }^{5}$ que serve como exemplo principal de uma tendência da época, que acompanha aquilo que era mais produzido no campo. O público que esse periódico buscava atingir ia do proprietário ao colono, mas também "o capitalista empreendedor do setor cafeeiro e as companhias exportadoras, tornando-se [um] impresso inestimável no quadro da economia da época" (2001, p. 289).

Assim, o segmento agronômico vinha num constante progresso no mercado jornalístico, alcançando grande importância por ser "responsável pela divulgação da política do setor agrícola e de seu beneficiamento técnico". Além disso, aproveitando-se do crescente desenvolvimento da propaganda, a revista tornou-se um veículo "publicitário dos mais efetivos" e, além disso, foi "através da porta do periodismo agrícola que se deu parte da colocação de produtos norte-americanos no Brasil, de utilidades domésticas a implementos agrícolas", uma vez que o periódico de tendência agrícola informava também "balanços e avaliações do comércio e indústria" (2001, p. 301).

Nota-se que pelas informações prestadas acima, uma pesquisa que se dedique ao estudo do periodismo agronômico pode ser muito útil tanto para perceber as tendências de desenvolvimento agrícola da época, como o desenvolvimento do mercado (a partir do exemplo da publicidade) do Brasil como um todo. Martins informa, ainda, que "a agricultura era uma das temáticas que exigia iniciativas" por parte da imprensa, uma vez que era uma “área de conhecimentos por desvendar, campo profícuo para atrair leitores, posto que se tratava do mais representativo assunto para o País” (2001, p. 283).

A supracitada autora, no entanto, ressalta que inicialmente circulavam especialmente periódicos de "leitura técnica, pouca aliás, sempre árida, na sua maioria boletins de governo". 6 Consoante a esta visão, Dias informa que as matérias eram "basicamente técnicas, políticas e de entrevistas". Além disso, diz o autor que "em todos os anos os prelos jorravam novo título de publicação na praça". Porém, assegura que "a maioria das publicações rurais durava no máximo um ano" (2011, p. 58). É válido dizer, no entanto,

\footnotetext{
${ }^{5}$ Publicação que inicialmente se chamava Revista Agrícola, órgão da Sociedade Pastoril e Agrícola, foi vendida em 1908 para o engenheiro Augusto Ramos que mudou o nome para $O$ Fazendeiro que circulou até 1921 (DIAS, 2011).

${ }^{6}$ Como veremos adiante, não é possível fazer grandes generalizações, pois houve algumas exceções, como os casos da revista $O$ Auxiliador da Indústria Nacional, ou mesmo d'A Lavoura.
} 
que boa parte dos periódicos (jornais ou revistas), qualquer que fosse sua segmentação temática, tinha um período de circulação bastante breve e essa característica do jornalismo do entresséculo XIX-XX, pode ser aplicada às revistas agronômicas, em razão de ser segmentada e ter um público muito especializado, o que certamente trazia inúmeras dificuldades para que pudessem circular por muito tempo.

O jornalista Eurico Santos, citado por João Castanho Dias, escreveu em artigo publicado em dezembro de 1922 na revista Ilustração Brasileira, que um dos principais motivos dos fracassos do mundo editorial agronômico residia no fato de que as "Empresas particulares que se abalançavam em aleatória iniciativa sentiam logo a indiferença, o desinteresse do público e nesse ambiente de gelo morriam não deixando outro fruto que um exemplo da inutilidade desses esforços". Além disso, Santos ressaltava que havia, ainda, o problema do analfabetismo, pois, segundo suas palavras, à época "o público mais letrado do interior do país ainda não se afeiçoou à leitura e o número de iletrados sobe a proporções que nos envergonham" (2011, p. 59).

Conforme já foi ressaltado, o marco do rompimento da acomodação desse público "desinteressado" foi a chegada da crise do café, que teria "obrigado", de certo modo, os fazendeiros a se interessarem por estudos sobre sua atividade. Segundo a autora, isso se deu a partir de 1895. Nesse sentido,

\begin{abstract}
A desordem registrada no campo, atingindo proprietário e mão-de-obra, demandou iniciativas de caráter oficial e providências particulares, que configuravam novas políticas agrícolas $[\ldots]$.

Abalava-se a comodista tradição do lavrador brasileiro [...] Lidar com a nova situação exigiu um proprietário mais informado e atento [...] Qualquer imprevisto interferia na produção, sobretudo as intempéries e pragas, que podiam pôr a perder toda uma safra. Por conta da broca; ou da geada [...] (MARTINS, 2001, p. 284).
\end{abstract}

Outras pesquisas têm apresentado novas perspectivas que vêm somar a este debate. Deste modo, além das questões apontadas por Martins, Roberta Barros Meira, por exemplo, indica que a partir da segunda década do século XIX, já havia a discussão em torno da necessidade de "reorganização da lavoura no Brasil" e, para que isso ocorresse, a chamada "agricultura científica" teve papel de destaque, tornando-se imprescindível para pensar os desafios daquele contexto. Segundo a autora, naquele momento o país “já não tinha condição de concorrer com outros países se não aplicasse aperfeiçoamentos técnicos possíveis na prática agrícola", ou seja, era necessário "modernizar a agricultura". Assim, diz ela, aplicar a ciência "para alcançar o progresso agrícola não era mais uma questão sujeita a discussões" e, nesse sentido, a despeito de todas as dificuldades para fazerem-se circular e sobreviver por várias edições, as revistas especializadas muito poderiam contribuir para os anseios do 
momento. Ainda segundo Meira, "não é difícil perceber que a divulgação dessas ideias [de evolução científica na agricultura] teve o seu lugar natural na imprensa" (MEIRA, 2012, p. 358-359).

Tal questão é tão importante que a historiadora faz referência a um fragmento de um artigo publicado na revista $O$ Auxiliador a Indústria Nacional, ${ }^{7}$ de 1853 , escrito por José Silvestre Rabello. ${ }^{8}$ Nesse texto, o autor tecia duras críticas a uma imprensa meramente opinativa, polêmica e emotiva, de tal maneira que ele esposava "a ideia de que deveria publicar mais coisas úteis que habilitassem o país e não como diariamente eram impressas 'parvoíces, sandices, mentiras, intrigas, vilanias, capazes de fazer arrepiar os cabelos até os jumentos "” (MEIRA, 2012, p. 2012, os grifos são da autora).

Para fazer uma ilustração ainda mais precisa (e que de certo modo confirma as informações prestadas por Meira), anos mais tarde, na primeira edição de 1881, houve um artigo escrito pelo diretor da redação d'O Auxiliador, Dr. Nicolau Joaquim Moreira, ${ }^{9}$ no qual o mesmo clamava por uma agricultura instrumentalizada para lidar com as inovações tecnológicas daquele tempo. Dizia ele que somente "pela instrução que se desenvolve a actividade do lavrador sobre as forças da natureza", de tal forma que, à agricultura, fazia-se fundamental acompanhar "os passos da sciencia; transformando os sólos, adaptando as culturas ás condições physicas da natureza e economicas da sociedade" ${ }^{10}$

Como vimos, nota-se a grande preocupação externada pelo autor com o ensino e uma agricultura renovada, científica. Portanto, mais uma vez, conforme informa Meira, no

\footnotetext{
${ }^{7}$ Essa publicação, segundo João Castanho Dias, foi a primeira revista agrícola do Brasil. Sua edição inaugural é datada do dia 15 de janeiro de 1833, circulando até a década de 1890 . Pelo que me consta, é certo que a referida revista circulou ao menos até o ano de 1896, edição de ${ }^{\circ} 61$, conforme os arquivos digitais da Biblioteca Nacional. Contudo, é válido dizer que segundo o mesmo autor informa, O Auxiliador "não foi pioneira da imprensa rural: esse feito coube ao Jornal da Sociedade de Agricultura, Comércio e Indústria da Província da Bahia, que surgiu em 1832 e morreu em 1833" (DIAS, 2011, p. 64). Ao que me parece, de fato foi o Jornal baiano o primeiro jornal agronômico brasileiro, pois Hélio Vianna (1945), em seu capítulo sobre a imprensa científica agrícola, faz tal indicação. Em Nelson Werneck Sodré (1977), encontramos alguns dados que corroboram a informação anterior, pois segundo o autor de A história da imprensa no Brasil: "No Salvador, em 1832, nova tentativa, agora provincial, de periódico sério, o Jornal da Sociedade de Agricultura, Comércio e Indústria da Província da Bahia" que "duraria até 1836, dirigido, até 1835, por Manuel Ferreira da Câmara Bittencourt e Sá e, com a morte deste, por Miguel Calmon du Pin e Almeida" (SODRÉ, 1977, p. 122).

${ }^{8}$ Segundo Sodré, José Silvestre Rabello foi um dos 27 sócios fundadores do IHGB - Instituto Histórico Geográfico Brasileiro, que, como se sabe, foi fundado sob os auspícios da Sociedade Auxiliadora da Indústria Nacional, responsável pela publicação da revista $O$ Auxiliador.

9 Segundo Silvio Lima, Nicolau Joaquim Moreira foi um médico que teve enorme preocupação com a racionalização da agricultura. Além disso, "participou ativamente dos mais importantes processos sociais das últimas décadas do século XIX. Foi nesse contexto que formou suas bases teóricas e iniciou sua vida social, intelectual e política. Lutou pela abolição da escravidão ao lado de José do Patrocínio, Joaquim Nabuco e André Rebouças, tendo participado das mais importantes instituições intelectuais do império. Foi também um dos mais combativos defensores da imigração europeia e, ainda, administrador da Capital Federal no alvorecer da República no Brasil" (2005, p. 45).

${ }^{10}$ O Auxiliador da Indústria Nacional. Sociedade Auxiliadora da Indústria Nacional, n. 1, janeiro de 1881. Os grifos são meus.
} 
último quartel do século XIX, ecoaram os discursos em prol do ensino profissional, cuja falta era listada como "um dos principais males que afligia a agricultura brasileira" e a presença da imprensa foi significativa, pois, conforme relata, "a proliferação das revistas agrícolas intensificou a produção de artigos que direta ou indiretamente discutiam essa questão" (MEIRA, 2012, p. 365). Este aspecto, como pudemos notar, é outra possibilidade fecunda de pesquisa, isto é, o desenvolvimento científico dos assuntos relacionados à agropecuária por meio das páginas do mercado revisteiro agronômico.

Segundo Sonia R. de Mendonça, havia quatro grandes "expedientes regeneradores" do mundo agrícola daquele momento, "o do povoamento/colonização; educação; modernização/racionalização produtiva e crédito/cooperativismo". Em relação à educação, por exemplo, a ideia era "regenerar o homem e elevar ao máximo a produtividade, tecnificando-a" (MENDONÇA, 1988, p. 83), metas essas que parecem ter sido preconizadas pela agricultura científica, e, evidentemente, a presença da imprensa foi de suma importância.

Acho válido ressaltar que processo semelhante - salvaguardando as especificidades de cada país - ocorreu no México do final do século XIX e início do XX, quando igualmente houve uma preocupação por parte de seus grupos dirigentes em alavancar a economia daquele lugar por meio da renovação agrícola. Conforme informa Maria Zuleta, a imprensa agronômica mexicana surgiu em meados dos oitocentos e, naquela época, havia um forte discurso que estava ligado à ideia de que a paz e a prosperidade material teriam que ser definidas como metas nacionais. Neste sentido, apesar de todo o atraso econômico mexicano, havia um "ideal del progreso material [que] se sustentó sobre una particular visión optimista de las 'inagotables' riquezas naturales del país", e o papel da imprensa agronômica foi central naquele momento, pois, junto com as estradas de ferro, a agricultura comercial surgia como atividade econômica fundamental, indo na esteira do desenvolvimento científico agrícola. Assim,

En este proceso, que por otra parte tuvo raíces no sólo en los acontecimientos politicos y económicos del país sino también en los cambios económicos que se desenvolvian a nivel mundial, las publicaciones especializadas en asuntos agrícolas desempeñaron un importante papel [...] sin embargo, se reprodujeron los argumentos que se venían propagando en el continente europeo desde mediado del siglo XIX, cuando la ciencia y la industria comenzaron a revolucionar definitivamente las formas de producción agrícola [...] Esta revolución [...] fue escalonada, se conoció en México a partir de un paradigma básico: el de la agricultura cientifica (ZULETA, 1991, p. 61).

Assim como no Brasil, a nova agricultura requeria agricultores instruídos com espírito de progresso econômico e técnico que alavancasse o desenvolvimento nacional, uma vez que havia um movimento ocorrendo em escala global, defende Zuleta, que buscava unir 
ciência e agricultura com o intuito de revolucionar as formas de produção agrícola. Ainda nas palavras da historiadora mexicana,

Los postulados básicos de esta nueva agricultura se resumían en tres. Primero, la imperativa aplicación de los adelantos científicos a las labores agrícolas para racionalizar unas tareas antes empiricas y rutinarias (agronomía, química, meteorología, botánica, parasitología, edafología, hidrología, mecánica), es decir, aplicación de la 'nueva preceptiva' agronómica de la época. En segundo lugar, se conceptuaba como imprescindible la creación de un conjunto de instituciones que tendrian por finalidad la divulgación de las nuevas técnicas y la asistencia y asesoría científica a los productores agricolas (...) En tercer término, se proponía que, como consecuencia del incremento de los volúmenes producidos en razón del cambio técnico, la comercialización agrícola se efectuara en mercados ampliados (ZULETA, 1991, p. 61).

Como é possível notar, a partir deste rápido, porém, significativo exemplo, as semelhanças com o que ocorria no Brasil eram consideráveis, especialmente nos três pontos destacados pela autora, uma vez que a agricultura não poderia mais prescindir do uso da ciência e, por consequência, da imprensa agrícola, do ensino agrícola, enfim, de uma porção de inovações necessárias para o progresso do campo. Conforme defende Henriques - no que diz respeito ao caso brasileiro - em razão dessa ligação com o cientificismo por parte de uma parcela do mundo agrícola, a

mentalidade dos agricultores brasileiros, no final do século XIX e início do XX, era colocada sob crítica severa de parte dos agrônomos e membros dessa intelectualidade, particularizando a rejeição que jazia dentro da classe dos agricultores aos recursos científicos e à educação técnica (HENRIQUES, 2010, p. 910).

Portanto, era preciso construir uma "mudança de mentalidade" no mundo do campo e a imprensa agrícola seria um importante componente nesse processo, tanto no caso do Brasil, como no mexicano.

Nos Estados Unidos, por sua vez, segundo informações da bibliografia especializada, a agricultural press surgiu por meio das chamadas agricultural societies. Conforme informa o historiador Donald Marti, foi a partir dos anos 1790 que começaram a circular informativos (bastante limitados à região de Boston) acerca do tema. $\mathrm{O}$ primeiro jornal agronômico teria sido, segundo o autor, o Massachusetts Agricultural Journal, publicado por volta de 1815 , restrito a um público muito pequeno. Marti informa que, ainda no século XIX, boa parte das publicações sofria com problemas financeiros e - tal como ocorria em terras brasileiras - tinham um curto "tempo de vida" e eram muito dependentes das sociedades agrícolas. ${ }^{11}$ No entanto, ressalta que, desde o início, “Agricultural journalism always meant to be serious, especially about Science and technology. It had several purposes,

\footnotetext{
${ }^{11}$ Marti indica que pelo menos até a terceira década do século XIX a situação manteve-se assim, sendo que depois disso houve uma maior independência dos periódicos agrícolas em relação às chamadas Sociedades agrícolas (1980, p. 28-37).
} 
more or less important to various editors and publishers, but it was always devoted to the spread of useful knowledge" (1980, p. 28). Carmen E. Clark, corroborando as ideias de Marti, informa que

The early [agricultural] press introduced new methods, data, technology, philosophical and moral attitudes about agriculture and farming. Newspapers reported on markets and exports, freely expressing opinions about agricultural issues. Almanacs allowed farmers to plan on the weather (CLARK, 2008, p. 10).

A situação exposta acima é mais uma que vem somar à história do periodismo agronômico na América. Conforme vimos a partir dos estudos mencionados no decorrer deste texto, o surgimento de um segmento editorial especialmente dedicado ao setor agrícola foi de fulcral importância para o desenvolvimento da agropecuária na economia brasileira e, pelo que pude perceber, algo muito semelhante ocorreu em pelo menos nos países acima mencionados.

Neste sentido, o que podemos notar é que o desenvolvimento da imprensa agronômica tem uma estreita relação com o progresso científico da agricultura e econômico nos países que ela se desenvolve. Deste modo, a seguir apresentarei algumas considerações mais próximas às pesquisas que empreendi, focando especial atenção a um período menos recuado no tempo e que corresponde a meados do século $\mathrm{XX}$.

\section{IMPRENSA AGRONÔMICA PÓS-METADE DO SÉCULO XX}

A revista que pesquisei com mais afinco (Brasil-Oeste) foi lançada apenas nos anos 1950 e, por esta razão, tive a oportunidade de levantar alguns dados sobre o periodismo agrícola daquele momento com o objetivo de trazer à luz informações que possam contribuir para futuras pesquisas que se dediquem a focar especial atenção sobre esse segmento editorial.

Num primeiro momento, é possível afirmar que se o jornalismo agronômico deu seus primeiros passos no final do século XIX, em meados do século XX atingiu o status de um dos mais segmentos editoriais de maior sucesso. Segundo Dias, assim como houve um maior desenvolvimento econômico no país nos anos 1950, o segmento editorial em apreço igualmente expandiu e, embora tenha havido especial atenção para a indústria, com "medidas destinadas a incentivar o desenvolvimento econômico, com ênfase na industrialização" (FAUSTO, 2001, p. 409), isso não significou "ausência de importância" para o setor agrícola (CASALECHI, 2002). Nos anos JK, por exemplo, os 31 objetivos desenvolvidos no interior de seu programa de metas estavam divididos em cinco grupos, dentre os quais, um deles era 
voltado para a produção de alimentos, por exemplo (FAUSTO, 2001, p. 422), ${ }^{12}$ indicando, por certo, que ainda havia especial atenção para o setor.

Nesse sentido, foi a partir daquele momento que houve efetivamente o início de uma "modernização da agricultura" e, ainda que somente a partir dos anos 1960 tenha ocorrido uma "efetiva" evolução tecnológica no campo, Casalecchi informa que entre os anos de 1954 e 1964 foi significativo o aumento da superfície cultivada em terras brasileiras. Segundo o autor, nesse ínterim, "a superfície cultivada aumenta em 56\%". Além disso, ressalta que houve

[...] um conjunto de medidas de políticas governamentais, objetivando o fornecimento de créditos e assistência técnica, favorecendo a importação de tratores, máquinas, ferramentas, fertilizantes e defensivos agrícolas, promovendo a melhoria da armazenagem e comercialização, e criando postos experimentais de técnica para a produção de sementes selecionadas.

O número de estabelecimentos que obtiveram crédito de custeio quadruplicou entre 1950 e 1960 e triplicou entre 1961 e 1965 (CASALECHI, 2002, p. 48-49).

Conforme informam Lucena e Souza, em uma leitura a respeito do desenvolvimento da agricultura do país nos anos 1950, o mundo do campo "teve como principal papel abastecer os centros urbanos e gerar divisas para financiar as importações necessárias à industrialização por substituição de importações". Nesse sentido, a grande preocupação da época fazer com que o campo "produzisse alimentos para suprir o setor urbano - em crescimento acelerado - e, assim, viabilizar o desenvolvimento industrial". Ainda segundo os autores, "a prioridade era abastecer o mercado interno, exportando-se apenas o excedente. Predominava, portanto, a monocultura exportadora, no caso, o café" (LUCENA, SOUZA, 2001, p. 181).

Na revista Brasil-Oeste, por exemplo, isso ocorria em três sentidos: o primeiro que servia para cobrar o poder público a buscar resoluções para os problemas no campo da agropecuária (quando se desenhava a ideia de agrobusiness); o segundo tratava de inserir o produtor dentro dos debates científicos a respeito da produção agrícola e, o terceiro, trazia questões relacionadas à evolução técnica e tecnológica da agropecuária. Trata-se de um contexto no qual se iniciou aquilo que se convencionou chamar de "revolução verde" que, segundo Zander Navarro, emerge entre 1950-1970, “após lenta acumulação de inovações anteriores, constituiu-se uma nova e acabada 'compreensão de agricultura' que gradualmente se tornou hegemônica em todo o mundo, não apenas no plano científico, mas nos diferentes sistemas agrícolas dos países que a ela aderiram". Assim, "materializou-se de fato sob um padrão tecnológico [rompendo] radicalmente com o passado por integrar fortemente as

\footnotetext{
12 Os outros quatro foram: energia, transportes, indústrias de base, educação, além, claro, da construção de Brasília (meta-síntese).
} 
famílias rurais a novas formas de racionalidade produtiva." Ainda nas palavras do autor, "esse período [...] é assim um divisor de águas também para as atividades agrícolas, e o mundo rural (re)nasceria fortemente transformado, tão $\operatorname{logo}$ os efeitos desta época de transformações tornaram-se completos". Outro fragmento que foi lembrado por Navarro e que pode nos servir para perceber melhor aquele contexto, chamava atenção para o fato de que aquela "noção de desenvolvimento rural [...] certamente foi moldada pelo 'espírito da época', com o ímpeto modernizante (e seus significados e trajetórias) orientando também as ações realizadas em nome do desenvolvimento rural" (NAVARRO, 2001, p. 84-85).

Mas como isso se deu em outras publicações agronômicas? Era efetivamente uma tendência? A mecanização da lavoura e a racionalização da produção eram as únicas vias defendidas pelo periodismo desse segmento? Estas são algumas das questões que podem ser lançadas, pois para o presente artigo, minha preocupação se dá muito mais em relação às revistas mais preocupadas com a grande propriedade.

Levando em consideração o que foi exposto acima, Dias afirma que efetivamente o "ponto de ignição de uma nova fase do setor [do periodismo agrícola] ocorreu na década de 1950", pois teria sido naquele momento que a imprensa rural havia sido "descoberta" "pelas editoras mais importantes do país, lançando suplementos e páginas em seus jornais e revistas de circulação nacional”. O jornalista indica que antes disso, o que havia era um debate relativamente secundário sobre a economia agrícola por meio da grande imprensa, pois "quem fazia [tal discussão] era a seção econômica ou a geral". Assim, estimulado "pela febre da soja, da cana-de-açúcar, da laranja, pelo moderno zebu, pelo frango de granja, pelo suíno do tipo carne, o campo conquistara enfim o espaço que nunca tivera nos matutinos das grandes capitais" (DIAS, 2011, p. 93).

Após a leitura dessas afirmações feitas pelo autor, busquei levantar dados que pudessem somar às suas contribuições. Assim, na página seguinte apresento um quadro que traz algumas das principais revistas agronômicas que circulavam no país entre os anos 1950 e 1960, por meio de uma lista de periódicos apresentada pelo Anuário Brasileiro de Imprensa (publicação riquíssima em informações a respeito do desenvolvimento da imprensa nacional e que traz dados muito relevantes).

O primeiro volume da supracitada publicação que consegui coletar é do ano de 1953. Muito provavelmente os periódicos ali listados, assim como nos anos seguintes, correspondiam aos de maior circulação ou prestígio no país, pois acredito que existia um número maior de revistas agrícolas naquele período. De todo modo, acredito que a 
apresentação que farei pode nos servir como uma sólida amostra do que se produzia na época nessa segmentação editorial.

Inicialmente, é preciso destacar quatro revistas principais no interior daquele nicho, sendo que três delas publicavam algo em torno de 20 mil exemplares por número e circulavam há certo tempo (Chácaras e Quintais, desde 1910; Agricultura e Pecuária, desde 1929; Sítios e Fazendas, desde 1936, e, curiosamente, a mais nova delas naquela ocasião, a revista Mundo Agrário, publicava a expressiva quantia de 50 mil por volume). Naquela edição do Anuário, foram listadas dezessete revistas. Nove delas eram de São Paulo, capital. Cinco delas eram do Rio de Janeiro, então Distrito Federal, duas de Belo Horizonte, Minas Gerais, e uma de Apucarana, no Paraná. ${ }^{13}$

No que diz respeito aos anuários de 1954/1955 e 1956/1957, os periódicos ali listados foram, do mesmo modo, de número dezessete (ainda que não fossem exatamente os mesmos da edição de 1953). No Quadro 1, mostro todas as revistas do segmento agronômico (além dos boletins, que igualmente eram listados) que foram arroladas pelo Anuário Brasileiro de Imprensa, correspondentes às edições de 1959 e 1961/1962, pois elas trouxeram um quadro de informações mais completo. Vejamos.

\section{Quadro 1}

Publicações (revistas e boletins) agronômicas listadas no Anuário Brasileiro de Imprensa (1959 e 1961/62)

\begin{tabular}{|c|c|c|c|c|c|c|c|}
\hline $\begin{array}{l}\text { Nome do } \\
\text { Periódico }\end{array}$ & Periodicidade & $\begin{array}{l}\text { Ano em } \\
\text { que foi } \\
\text { criada }\end{array}$ & $\begin{array}{c}\text { Valor da } \\
\text { publicidade } \\
\text { por página } \\
\text { em } 1959\end{array}$ & $\begin{array}{c}\text { Valor da } \\
\text { publicidade } \\
\text { por página } \\
\text { em } 1960\end{array}$ & $\begin{array}{c}\text { Tamanho } \\
\text { (1959) }\end{array}$ & $\begin{array}{c}\text { Tamanho } \\
(\mathbf{1 9 6 0 )}\end{array}$ & Local \\
\hline A granja & Mensal & 1944 & Cr $\$ 5.000,00$ & Cr\$ 8.000,00 & $27 \times 18$ & $23,5 \times 15$ & RS \\
\hline A lavoura & Bimestral & 1897 & Cr\$ 5.000,00 & $\mathrm{Cr} \$ 6.000,00$ & $22 \times 15$ & $22 \times 15$ & $\mathrm{DF} / \mathrm{GB}$ \\
\hline A rural & Mensal & 1920 & Não informa & Não informa & $32 \times 23$ & $32 \times 23$ & SP \\
\hline $\begin{array}{l}\text { Anuário dos } \\
\text { Criadores }\end{array}$ & Anual & $\begin{array}{c}\text { Não } \\
\text { informa }\end{array}$ & $\begin{array}{l}\text { Não estava na } \\
\text { lista }\end{array}$ & $\begin{array}{l}\text { Cr\$ } \\
30.000,00\end{array}$ & $22 \times 14,5$ & $22 \times 14,5$ & $\mathrm{SP}$ \\
\hline $\begin{array}{l}\text { Agricultura e } \\
\text { Pecuária }\end{array}$ & Mensal & 1929 & Cr\$ 9.000,00 & Não informa & $\begin{array}{c}27,3 \times 18 \\
7\end{array}$ & $27,3 \times 18,7$ & DF/GB \\
\hline $\begin{array}{l}\text { Anuário } \\
\text { Agrícola } \\
\text { Brasileiro }\end{array}$ & Anual & 1953 & $\mathrm{Cr} \$ 8.000,00$ & $\begin{array}{l}\text { Não estava } \\
\text { na lista }\end{array}$ & $\begin{array}{c}23,5 \times 16 \\
5\end{array}$ & $\begin{array}{c}\text { Não } \\
\text { estava na } \\
\text { lista }\end{array}$ & $\mathrm{SP}$ \\
\hline Boletim Faresc & Mensal & 1959 & $\begin{array}{l}\text { Não estava na } \\
\text { lista }\end{array}$ & Cr\$ $4.000,00$ & $\begin{array}{c}\text { Não } \\
\text { estava na } \\
\text { lista } \\
\end{array}$ & $23 \times 16$ & $\mathrm{SC}$ \\
\hline Brasil-Oeste & Mensal & 1956 & Cr\$ 8.000,00 & $\begin{array}{l}\text { Cr\$ } \\
11.000,00\end{array}$ & $27 \times 18,5$ & $27 \times 18,5$ & SP \\
\hline Brasil Rural & Mensal & 1946 & $\mathrm{Cr} \$ 5.000,00$ & Não informa & $\begin{array}{c}16,2 \times 10 \\
8\end{array}$ & $16,2 \times 10,8$ & SP \\
\hline
\end{tabular}

\footnotetext{
${ }^{13}$ Anuário Brasileiro de Imprensa, da Revista Publicidade \& Negócios, 1953.
} 
174

\begin{tabular}{|c|c|c|c|c|c|c|c|}
\hline $\begin{array}{l}\text { Brincar e } \\
\text { Aprender }\end{array}$ & Trimestral & $\begin{array}{c}\text { Não } \\
\text { informa }\end{array}$ & $\begin{array}{l}\text { Não estava na } \\
\text { lista }\end{array}$ & Não informa & $\begin{array}{c}\text { Não } \\
\text { estava na } \\
\text { lista }\end{array}$ & $18 \times 26$ & GB \\
\hline Carta Semanal & Semanal & $\begin{array}{c}\text { Não } \\
\text { informa }\end{array}$ & $\begin{array}{l}\text { Não estava na } \\
\text { lista }\end{array}$ & Não informa & $\begin{array}{c}\text { Não } \\
\text { estava na } \\
\text { lista }\end{array}$ & $16 \times 23$ & GB \\
\hline $\begin{array}{l}\text { Chácaras e } \\
\text { Quintais }\end{array}$ & Mensal & 1910 & Cr\$ $10.000,00$ & $\begin{array}{l}\text { Cr\$ } \\
12.000,00\end{array}$ & $19 \times 13$ & $19 \times 13$ & SP \\
\hline $\begin{array}{l}\text { Informação } \\
\text { Agrícola }\end{array}$ & Mensal & $\begin{array}{c}\text { Não } \\
\text { informa }\end{array}$ & $\begin{array}{l}\text { Não estava na } \\
\text { lista }\end{array}$ & Não informa & $\begin{array}{c}\text { Não } \\
\text { estava na } \\
\text { lista }\end{array}$ & $\begin{array}{c}\text { Não } \\
\text { informa }\end{array}$ & GB \\
\hline $\begin{array}{l}\text { FIR (Revistas } \\
\text { de } \\
\text { Fertilizantes, } \\
\text { inseticidas e } \\
\text { racões) }\end{array}$ & Mensal & 1958 & Não informa & $\mathrm{Cr} \$ 8.500,00$ & $17 \times 13$ & $23 \times 16$ & SP \\
\hline Gado holandês & Mensal & 1936 & Cr\$ 5.000,00 & $\mathrm{Cr} \$ 6.000,00$ & $24 \times 15,5$ & $24 \times 15,5$ & SP \\
\hline Gleba & Mensal & 1955 & $\mathrm{Cr} \$ 4.000,00$ & Não informa & $23 \times 16$ & $23 \times 16$ & $\overline{\mathrm{DF}}$ \\
\hline $\begin{array}{l}\text { Lavoura e } \\
\text { Criação }\end{array}$ & Mensal & 1946 & Cr\$ $\$ 6.000,00$ & Cr\$ $\$ 8.000,00$ & $26 \times 18$ & $22,5 \times 15$ & SP \\
\hline $\begin{array}{l}\text { Minas } \\
\text { Agrícola }\end{array}$ & Mensal & 1952 & $\begin{array}{l}\text { Não estava na } \\
\text { lista }\end{array}$ & $\begin{array}{l}\text { Cr\$ } \\
10.000,00\end{array}$ & $\begin{array}{c}\text { Não } \\
\text { estava na } \\
\text { lista }\end{array}$ & $22 \times 15$ & MG \\
\hline $\begin{array}{l}\text { Mundo } \\
\text { Agrário }\end{array}$ & Mensal & 1953 & Cr\$ $13.000,00$ & Não Informa & $30 \times 22$ & $30 \times 22$ & $\mathrm{DF}$ \\
\hline $\begin{array}{l}\text { Mundo } \\
\text { Agrícola }\end{array}$ & Mensal & 1958 & Cr\$ $\$ 8.000,00$ & Não informa & $\begin{array}{c}23,5 \times 16, \\
5\end{array}$ & $23,5 \times 16,5$ & SP \\
\hline $\begin{array}{l}\text { Revista dos } \\
\text { Criadores }\end{array}$ & Mensal & 1930 & $\mathrm{Cr} \$ 8.000,00$ & $\begin{array}{l}\mathrm{Cr} \$ \\
15.000,00\end{array}$ & $31 \times 22,5$ & $23,5 \times 18,5$ & SP \\
\hline Revista Rural & Mensal & 1957 & Cr\$5.000,00 & Não informa & $28 \times 21$ & $28 \times 21$ & $\mathrm{RJ}$ \\
\hline Rio Rural & Mensal & 1957 & Não informa & Não informa & $23 \times 16,5$ & $23 \times 15,5$ & $\overline{D F}$ \\
\hline $\begin{array}{l}\text { São Paulo } \\
\text { Agrícola }\end{array}$ & Não informa & $\begin{array}{c}\text { Não } \\
\text { informa }\end{array}$ & $\begin{array}{l}\text { Não estava na } \\
\text { lista }\end{array}$ & $\begin{array}{l}\text { Cr\$ } \\
15.000,00\end{array}$ & $\begin{array}{c}\text { Não } \\
\text { estava na } \\
\text { lista }\end{array}$ & $\begin{array}{c}\text { Não } \\
\text { informa }\end{array}$ & SP \\
\hline $\begin{array}{l}\text { Seleções } \\
\text { Agrícolas }\end{array}$ & Mensal & 1946 & Cr $\$ 4.000,00$ & Cr\$ 5.000,00 & $16 \times 11$ & $16 \times 11$ & $\mathrm{DF}$ \\
\hline $\begin{array}{l}\text { Sítios e } \\
\text { Fazendas }\end{array}$ & Mensal & 1936 & Cr\$ $12.000,00$ & Não informa & $23 \times 15$ & $23 \times 15$ & SP \\
\hline Zebu & Mensal & 1953 & $\mathrm{Cr} \$ 4.500,00$ & $\mathrm{Cr} \$ 6.000,00$ & $23,5 \times 16$ & $23,5 \times 16$ & $\mathrm{MG}$ \\
\hline
\end{tabular}

Fonte: Anuário Brasileiro de Imprensa (1959 e 1961/1962).

As informações contidas no quadro acima possibilitam fazer algumas deduções. Por exemplo, das vinte e sete publicações, em cinco delas não existe a informação da data de sua fundação. No entanto, em relação àquelas em que tais dados foram informados, ou seja, das vinte e duas que restam, onze foram lançadas nos anos 1950, quatro nos anos 1940, três nos anos 1930, duas dos anos 1920, uma em 1910 e outra no final dos anos 1890. Nesse sentido, a metade corresponde à década de 1950 e tal informação pode ser um indicativo de que o mercado jornalístico agrícola realmente estava em ascensão naquele momento, com a produção de novos títulos. 
Levando em consideração todas as edições analisadas do Anuário Brasileiro de Imprensa (posteriormente, Anuário de imprensa, rádio e televisão) que pude consultar (1953, 1954/55, 1956/57, 1958, 1959, 1961/62), trinta e dois periódicos agronômicos foram listados, dentre os quais oito não informavam a data de fundação. Assim, em vinte e quatro deles constava tal dado e aqueles que foram lançados nos anos 1950 correspondiam a $48 \%$ do total, mais uma vez indicando a ascensão do mercado jornalístico da época para os assuntos agropecuários em revista.

Além de sua importância como veículo de informação propriamente dito, conforme já tive oportunidade de mencionar em outro momento, a partir do século XX a imprensa agrícola foi um dos canais mais importantes para a divulgação dos anúncios publicitários. É importante lembrar que nos anos 1950, houve um avanço considerável na produção de bens de consumo duráveis no país, além da produção de veículos automotivos e máquinas agrícolas, fazendo do mercado revisteiro agronômico um segmento muito atraente para os anunciantes.

A importância em analisar a publicidade não reside somente para perceber o seu progresso ou transformação no interior do desenvolvimento econômico de um país. Segundo Barzotto, que tratou de associação do conteúdo discursivo e a propaganda em um conjunto de revistas agronômicas, "há uma completa predominância da publicidade nas revistas destinadas ao meio rural [...] não só da publicidade de produtos, mas de uma concepção de sociedade, tanto através de peças publicitárias como também através das matérias publicadas" (1997, p. 12 , os grifos são meus).

Nesse sentido, a ideia de que havia uma "concepção de sociedade" parece ser bastante ilustrativa, pois era justamente disso que se tratava quando pesquisei a Brasil-Oeste e entrei em contato com outros periódicos de mesmo segmento. $\mathrm{O}$ alinhamento dos discursos imagético e textual, das propagandas e da linha editorial da revista pretendiam justamente atuar como um canal que apresentava uma série de representações e visões de mundo na tentativa de incutir em seus leitores a ideia de que aquele caminho (de "progresso", "desenvolvimento econômico", "cientifização no campo"; "revolução verde", etc.) era inevitável. Portanto, não se tratava apenas de informar seu público, mas de indicar os caminhos - no âmbito da agropecuária - que deveriam necessariamente serem trilhados.

Dito isto, é importante trazer as considerações feitas por André de Seguin des Hons, por exemplo, pois ele considerava que dentro daquilo que ele denomina de "la presse professionnelle, scientifique ou technique" (a imprensa profissional, científica ou técnica), havia três segmentos jornalísticos principais, ou "secteurs clefs" (setores-chave) no interior da 
imprensa brasileira: o relacionado à agricultura, à tecnologia industrial e à saúde. $\mathrm{O}$ historiador francês separa os periódicos agronômicos em três momentos de evolução, correspondentes aos anos de 1955, 1965 e 1978. Por ora, cito apenas as informações prestadas pelo autor em relação aos dois primeiros períodos, que estão inseridos no recorte temporal em que circulou a revista Brasil-Oeste. Des Hons fez uso do Anuário Brasileiro de Imprensa e do Anuário Estatístico do Brasil, apresentando os seguintes dados:

Agriculture et Elevage. En 1955, parmi les 17 publications périodiques citées par l'Anuário Brasileiro de Imprensa (...) La somme de leurs tirages indique sur une période d'un an un total de 2.245.000 exemplaires. ${ }^{14}$

En 1965 L'Anuário Estatístico do Brasil indique l'existence de 32 publications avec un total annuel de 3.053.000 exemplaires (HONS, 1985, p. 41).

Em busca de mais informações, procurei subsídios nos Anuários Estatísticos do Brasil dos anos de 1965, 1966, 1967, correspondentes a 1963, 1964, 1965 e 1966. Em relação ao ano de 1963, havia 28 periódicos agronômicos; em 1964, 30; em 1965, 32; e em 1967, 35. No que diz respeito à tiragem média, entre 1963 e 1964 é possível notar um aumento considerável, pois se no primeiro ano os 28 periódicos publicavam em média a quantia de 386.100 exemplares mensais, no ano seguinte aumentou consideravelmente para 589.070 mil, distribuídos entre 30 periódicos.

Nesse sentido, levando em consideração o número de 386.100 exemplares correspondentes aos 28 periódicos, que representava a média mensal da totalidade deles, em 1963, a imprensa agronômica produzia a quantia de 12 vezes 386.100, o que corresponde a 4.633.200 exemplares. Já no ano seguinte (1964), os 30 periódicos produziram a quantia de 7.068.840 exemplares anualmente. Em relação aos anos de 1965 e 1966, o Anuário apresentava a tiragem total anual de $3.063 .754^{15}$ (32 periódicos) e 4.352 .790 (35 periódicos), respectivamente. Isso indica que houve um declínio em relação à 1964 no que tange ao número de exemplares publicados, mas uma maior quantidade de diferentes títulos em circulação. Ainda assim, as agronômicas ${ }^{16}$ mantiveram média mais alta frente às publicações das ciências da saúde e muito próxima da área de Tecnologia e Indústrias, se forem levados em consideração os exemplos dados por Hons, tal como é possível notar a seguir:

Quadro 2

Comparativo entre periódicos de diferentes segmentos jornalísticos nos anos de 1965 e 1966

\begin{tabular}{|c|c|c|c|c|c|c|}
\hline Segmento & $\begin{array}{l}\text { Número de } \\
\text { periódicos }\end{array}$ & $\begin{array}{c}\text { Número de } \\
\text { periódicos }\end{array}$ & $\begin{array}{c}\text { Tiragem total } \\
(\mathbf{1 9 6 5 )}\end{array}$ & $\begin{array}{c}\text { Tiragem } \\
\text { total (1966) }\end{array}$ & $\begin{array}{c}\text { Média de } \\
\text { tiragem de }\end{array}$ & $\begin{array}{c}\text { Média de } \\
\text { tiragem de }\end{array}$ \\
\hline
\end{tabular}

\footnotetext{
${ }^{14}$ Importante dizer que, no Anuário Brasileiro de Imprensa, não era sempre que a informação sobre a tiragem de todos os periódicos listados era revelada.

${ }^{15}$ Como vimos, há uma pequena diferença em relação aos dados apresentados por André Seguins des Hons.

${ }^{16}$ É importante, contudo, fazer uma ressalva a esse respeito, tendo em vista que esse segmento, tal como aparece nos dados, inclui publicações de caça e pesca, que não representa necessariamente os periódicos agronômicos, mas entra no âmbito da produção animal.
} 


\begin{tabular}{|c|c|c|c|c|c|c|}
\hline & (1965) & (1966) & & & $\begin{array}{c}\text { exemplares } \\
\text { por título } \\
\text { (1965) }\end{array}$ & $\begin{array}{c}\text { exemplares por } \\
\text { título } \\
\text { (1966) }\end{array}$ \\
\hline $\begin{array}{c}\text { Agricultura, } \\
\text { Silvicultura, } \\
\text { Pecuária, Caça } \\
\text { e Pesca }\end{array}$ & 32 & 35 & 3.063 .754 & 4.352 .790 & 95.742 & 124.365 \\
\hline $\begin{array}{c}\text { Ciências } \\
\text { médicas, } \\
\text { higiene pública }\end{array}$ & 28 & 25 & 1.885 .922 & 1.891 .589 & 67.354 & 75.663 \\
\hline $\begin{array}{c}\text { Tecnologia, } \\
\text { Indústrias, } \\
\text { Artes e Ofícios }\end{array}$ & 40 & 35 & 4.436 .152 & 4.595 .150 & 110.903 & 131.290 \\
\hline
\end{tabular}

Fonte: Anuário Estatístico do Brasil (1967).

Nota-se que enquanto houve uma queda no número de periódicos relacionados à saúde e à tecnologia, os agronômicos, por sua vez, tiveram um incremento na quantidade de títulos e um enorme acréscimo de exemplares lançados, enquanto os outros segmentos citados cresceram muito pouco em termos de tiragem.

Outro dado importante apresentado por Hons (1985) foi a compilação das informações do Anuário Estatístico do Brasil de 1980 (que correspondia aos dados de 1978). Naquele momento, havia algo em torno de 74 periódicos agronômicos que totalizavam a publicação de 11.810.000 exemplares/ano, isto é, muito mais do que os periódicos de Tecnologia e Indústria (5.307.000 exemplares/ano) e acima daqueles relacionados à saúde (10.714.000 exemplares/ano), indicando, outra vez, a força daquele segmento editorial.

Ao que me parece, a imprensa brasileira especializada em assuntos agropecuários seguia uma tendência internacional de crescimento. Em estudo feito pelo historiador francês André-Jean Tudesq acerca do periodismo agrícola francês, o autor comenta, por exemplo, que as "relations entre les moyens d'information et le monde agricole entre 1945 et 1980 se sont déroulées dans un contexte en mutations souvent brutales. Les media ont été à la fois les générateurs et les traducteurs de l'ouverture du monde agricole sur l'extérieur" (1988, p. 205).

Tudesq indica, ainda, que no período citado houve considerável avanço de leitores do mundo rural, tanto em relação à imprensa geral, quanto no que diz respeito àquela especializada em agricultura. Assim, dizia ele que a "presse écrite est, pendant toute la période envisagée, le moyen d'information qui s'adresse le plus aux agriculteurs" (TUDESQ, 1988, p. 206), uma vez que a mesma se tornava uma ferramenta efetiva de trabalho. Mais uma vez, nas suas palavras,

La presse agricole est devenue un instrument de travail pour les agriculteurs qui y trouvent à la fois des renseignements sur la mécanisation ou les techniques agricoles, sur l'information économique agricole (les marchés, les cours...) sur leurs associations et la politique agricole (1988, p. 207). 
Como já mostrei, tanto a imprensa agrícola mexicana quanto a estadunidense tiveram especial participação no incremento da agropecuária daqueles países no crepúsculo do século XIX. Ainda que no exemplo acima trato de apresentar a situação da França já no período correspondente à metade do século $\mathrm{XX}$, trata-se de um desenvolvimento semelhante. A partir dos dados indicados nas páginas anteriores, nota-se que no Brasil o impacto dos anos 1950 e 1960 teve total relação com as inovações tecnológicas no campo e o início da implementação de máquinas agrícolas motorizadas.

Quando comecei a pesquisar a Brasil-Oeste, pude notar que os aspectos e as características mencionadas nas páginas anteriores a respeito da preocupação central da imprensa agrícola poderiam ser aplicados a ela, isto é, a ideia de que ali pretendia-se criar um "novo Brasil" ou uma "nova agricultura", etc. É claro que para o caso da supracitada revista, havia uma inquietação de tipo especial, pois apesar de ter sido um periódico produzido em São Paulo (SP), preocupava-se bastante com o desenvolvimento agropecuário de Mato Grosso.

A partir da leitura da realidade vivida por Mato Grosso, pretendia-se "explicar" as causas daquilo que eles julgavam "atrasado" e propor projetos de modernização, especialmente no âmbito do potencial da agropecuária. Os desígnios do periódico deveriam estar alinhados à tarefa de trabalhar em favor do desenvolvimento do oeste brasileiro, tal como pode ser percebido em trechos como o que citarei a seguir:

Nossa revista tem uma finalidade precípua: tornar mais conhecida e melhor compreendida a vasta região do Centro-Oeste brasileiro, compreendida pelos Estados de Mato Grosso e Goiás. [...] De modo geral, entretanto, merecerão acolhimento, em nossas colunas, todos os fatos relacionados com os Estados que confinam com Mato Grosso, dada a identidade de interêsses que existe entre êles [...] Particular interêsse merecerão de nossa parte os assuntos agropecuários, pois que nesse ramo de atividades se fundamenta a parcela mais ponderável da economia dos Estados do Centro-Oeste. ${ }^{17}$

Esse texto deixava claro quais eram os "desígnios" daquele projeto editorial encampado, isto é, trabalhar em prol dos interesses da região oeste do país. Quando $o$ manifesto-programa sugere que "todos os problemas geoeconômicos" seriam estudados de modo que, "através de uma honesta difusão de opiniões", fosse encontrada uma solução "adequada e justa", percebe-se que a Brasil-Oeste era uma possibilidade encarada pelos seus idealizadores como perfeitamente apta a alocar Mato Grosso e o Centro-Oeste do Brasil no lugar em que mereciam estar, isto é, no rumo do desenvolvimento econômico. É por meio da palavra escrita que tal projeto vai se ilustrar.

\footnotetext{
${ }^{17}$ Revista Brasil-Oeste, ano I, n ${ }^{\circ}$, janeiro de 1956, São Paulo (SP), p. 2. Os grifos são meus.
} 
Ao observarmos os textos da Brasil-Oeste, a agricultura brasileira - e, especialmente a mato-grossense - só conseguiria atingir um outro nível se incorporasse os novos valores do campo. Do contrário, Mato Grosso não alcançaria o status de "celeiro do mundo". Germinava, portanto, a ideia de revolução no campo, que mais tarde seria a já mencionada "revolução verde", que preconizava o produzir mais, para lucrar mais. Os textos, em sua maioria, tinham caráter informativo e instrutivo, pois pretendiam apresentar ao almejado "novo produtor" rural as potencialidades que haveriam naquela nova maneira de produzir e trabalhar no campo, mais eficaz e rápida.

Dentre as inúmeras reportagens publicadas pela Brasil-Oeste, várias delas buscavam pensar, diagnosticar os problemas e propor soluções para o campo. Assim, o atraso deveria ser superado sofisticando a produção agrícola, o maior trunfo de Mato Grosso para o Brasil, defendiam eles. A atuação da revista certamente contribuiu para construir e fortalecer um discurso que nos dias atuais é mais forte do que naquele tempo, isto é, a concepção de que Mato Grosso e Mato Grosso do Sul são dois dos maiores "celeiros" do país no âmbito da agricultura, além de figurarem também dentre os estados com maior rebanho de bovinos em terra nacional, fomentando historicamente a representação de que nessa região "sempre houve" uma "vocação agrícola/agropecuária". Os resultados, como é amplamente conhecido, são os mais problemáticos possíveis, pois o chamado agronegócio aparece como a única alternativa possível e, dessa visão de mundo decorre uma porção de contradições que, pelas limitações deste artigo não podem ser contempladas, mas que dizem respeito aos conflitos no campo e devastação ambiental, só para citarmos dois exemplos.

\section{CONSIDERAÇÕES FINAIS}

Como mencionei no início deste artigo, não pretendi aqui discutir detalhadamente a revista Brasil-Oeste e a remissão que fiz há pouco serviu muito mais para resumir algumas possibilidades que encontrei quando a pesquisei. Ademais, busquei evidenciar a preocupação que historicamente reside nessa segmentação editorial com o desenvolvimento econômico, a cientifização da agricultura, a tecnologização da mesma, o desenvolvimento da publicidade e a concepção de sociedade que dela emana.

Neste sentido, o periodismo agronômico pode ser percebido como uma importante fonte de pesquisa, mas, além disso, tais publicações são melhor compreendidas se elencadas como objetos de pesquisa, especialmente para percebermos como os grupos que nas redações se aglutinavam, pensavam propostas e projetos "para a nação". É claro que, além disso, outros 
aspectos podem ser percebidos, inclusive para uma compreensão maior a respeito da história da imprensa no Brasil.

Assim, acredito que futuros trabalhos, preocupados em desvendar as relações entre o desenvolvimento econômico brasileiro, a cultura agrícola criada e os discursos "naturalizantes" sobre a dita "vocação natural" brasileira à agropecuária - depois convertida em agrobusiness -, poderão somar às pesquisas que até o momento foram desenvolvidas que, pelas buscas que fiz, ainda são muito escassas em comparação ao exorbitante número de publicações do segmento editorial em tela que se abre para os historiadores da imprensa.

\section{FONTES}

Anuário Brasileiro de Imprensa, da Revista Publicidade \& Negócios, 1953, Rio de Janeiro (RJ).

Anuário de imprensa, rádio \& televisão, Emprêsa Jornalística PN S.A, 1958, Rio de Janeiro (RJ).

O Auxiliador da Indústria Nacional. Sociedade Auxiliadora da Indústria Nacional, n. 1, janeiro de 1881, Rio de Janeiro (RJ).

Anuário Estatístico do Brasil (várias edições).

Revista Brasil-Oeste, ano I, n 1, janeiro de 1956, São Paulo (SP).

\section{REFERÊNCIAS}

ANTUNIASSI, M. H. R.; MORAES, Maria Isabela G. L. A revista Chácaras e Quintaes e a comunicação rural. Cadernos CERU (USP), v. 16, p. 183-192, 2005.

BARZOTTO, Valdir. Leitura de propaganda de agrotóxicos. Contribuição aos estudos da ideologia da modernização. 1992. 107 f. Dissertação (Mestrado em Linguística) - Curso de Pós-Graduação em Linguística, Universidade Estadual de Campinas. Campinas.

BEDIAGA, Begonha. Revista Agrícola (1869-1891): sensibilizar o lavrador e plantar ciências agrícolas. Varia História (UFMG. Impresso), v. 29, p. 169-195, 2013.

CAPELATO, Maria H. Rolim. Imprensa e História do Brasil. São Paulo: Contexto; Editora da Universidade de São Paulo, 1988.

; PRADO, Maria Ligia. O bravo matutino: imprensa e ideologia no jornal O Estado de S. Paulo, São Paulo, Alfa-Omega, 1980.

. Imprensa e história do Brasil. São Paulo: Contexto/EDUSP, 1988.

CARONE, Edgar. O Centro Industrial do Rio de Janeiro e a sua importante participação na economia nacional (1827-1977). Rio de Janeiro: Cátedra. 1978

CASALECHI, Ênio. O Brasil de 1945 ao Golpe Militar. São Paulo-SP: Contexto, 2002.

CLARK, Carmen E. Agricultural Press. In: VAUGHN, Stephen L. (editor). Encyclopedia of American Journalism. New York, Taylor \& Francis Group, LLC, 2008 
CORREAA, Ana Maria M. Prefácio. In: LUCA, Tania Regina de. A Revista do Brasil: um diagnóstico para a (N)ação. São Paulo: Ed. UNESP, 1998.

CRUZ, Helena F.; PEIXOTO, Maria do Rosário C. Na oficina do historiador: conversas sobre história e imprensa. Projeto História, São Paulo, n.35, p. 235-270, dez. 2007.

DIAS, João Castanho. A imprensa rural no Brasil. Histórias da agricultura e da propaganda agrícola. Ed. Barleus, 2011.

FAUSTO, Boris. História do Brasil. São Paulo-SP, EdUSP, 9a . ed., 2001.

FERRARO, MÁRIO R. O papel da Revista Agrícola no processo de modernização da agricultura paulista, no final do século XIX. In: $10^{\circ}$ Encontro Nacional de História da Mídia, 2015, Porto Alegre. Anais do $10^{\circ}$ Encontro Nacional de História da Mídia, 2015.

GOMES, Ângela de Castro. Essa gente do Rio...: modernismo e nacionalismo. Rio de Janeiro: Editora FGV, 1999.

HENRIQUES, Amilson B. A cultura rotineira e a lavoura racional: proposições na Revista Agrícola (São Paulo, 1895-1907). 2010. 272f. Dissertação (Mestrado em História). Curso de Pós-graduação em História, Universidade Estadual Júlio de Mesquita Filho. Assis.

KIRCHER, Mirta. La prensa escrita: actor social y político, espacio de producción cultural y fuente de información histórica. Revista de História, n. 10, 2005.

LENOBLE-BART, Annie. André-Jean. Tudesq: a pioneer of the study of the media in French-speaking Africa. Ecquid Novi: African Journalism Studies. Vol. 33, Issue 3, pp 93-97, 2012.

LUCA, Tania Regina de. A grande imprensa na primeira metade do século XX. In:

Paulo: Contexto, 2008. ; MARTINS, Ana Luiza (Org.). História da Imprensa no Brasil. São

; MARTINS, Ana Luiza (Org.). História da Imprensa no Brasil. São

Paulo: Contexto, 2008.

. História dos, nos e por meio dos periódicos. In: PINSKY, Carla Bassanezi (Org). Fontes Históricas. São Paulo: Contexto, 2005.

MARTI, Donald. Agricultural journalism and the diffusion of knowledge: the first halfcentury in America. Agricultural History, vol. 54, n. 1, p. 28-37, 1980.

MARTINS, Ana Luiza. "Chácara e Quintais revisitada". In: 95 anos. Edição Histórica Gessulli Agribusiness. As grandes marcas que construíram o agronegócio brasileiro. São Paulo: Editora Gessuli, 2004.

MARTINS, Ana Luiza. "No País Agrícola, revistas agronômicas”. In: MARTINS, Ana Luiza, Revistas em revista: imprensa e práticas culturais em tempos de República. 1890-1922. São Paulo: EDUSP/FAPES/IMESP, 2001

MARTINS, Ana Luiza. Da fantasia à história: folheando páginas revisteiras. História. São Paulo, 22 (1): 59-79, 2003.

MEIRA, Roberta B., A quimera da modernização: do terceiro distrito de engenhos centrais ao complexo agroindustrial sucroalcooleiro paulista, mineiro e fluminense (1875-1926). 2012. 457f. Tese (Doutorado em História), Programa de Pós-Graduação em História Econômica, Universidade de São Paulo. São Paulo.

MENDONÇA, Sonia R. O ruralismo brasileiro (1883-1931). São Paulo-SP, Hucitec, 1998. 
PAIVA, Evelyn Morgan M. O campo em revista: agrarismo e modernismo no Estado do Rio de Janeiro nos anos de 1920' 15/09/2014. 2014. 244 f. Doutorado em História, Política e Bens Culturais Instituição de Ensino: Fundação Getúlio Vargas/RJ, Rio de Janeiro.

SALGUEIRO, Eduardo de Melo. “O maior projeto em prol de Mato Grosso”: uma análise da revista Brasil-Oeste (1956-1967). 2011. 183f. Dissertação (Mestrado em História) - Programa de Pós-Graduação em História, Universidade Federal da Grande Dourados, Dourados.

. Fausto Vieira de Campos, a revista Brasil-Oeste e seu projeto para Mato Grosso. 2016, 286f. Tese (Doutorado em História). - Programa de Pós-Graduação em História, Universidade Federal da Grande Dourados, Dourados.

SANTOS, Fabrícia de Oliveira. A "Revista Agrícola, órgão da sociedade sergipana de Agricultura" e a estratégia da produção e organização do campo em Sergipe, 1905-1908: "por em commum as 'luzes' e experiências". 2012. 432f. Tese (Doutorado em Geografia). Programa de Pós-Graduação em Geografia, Universidade Federal do Sergipe. São Cristóvão.

SILVA, José Luiz Werneck da. Isto é o que lhe parece. 1979. Dissertação (Mestrado) Instituto de ciências humanas e filosofia, UFF, Niterói, 1979.

SODRÉ, Nelson W. História da imprensa no Brasil. Rio de Janeiro: Mauad, 1998.

SOUZA LIMA, Silvio C. de. Determinismo biológico e imigração chinesa em Nicolau Moreira (1870-1890). 2005. 123f. Dissertação (Mestrado em História das Ciências da Saúde), Programa de Pós-Graduação em Ciências da Saúde, FIOCRUZ, Rio de Janeiro.

SOUZA, Bruno Rangel Capile de. A mais santa das causas: a revista agrícola do imperial instituto fluminense de agricultura (1869-1891). 2010. 145f. Mestrado (História das ciências e das técnicas e epistemologia instituição de ensino), Universidade Federal do Rio de Janeiro. Rio de Janeiro.

TEMPERINI, Rosana Soares de Lima. O sertão vai virar campo: análise de um periódico agrícola (1930-1937). 2003. 104f. Dissertação (Mestrado em História das Ciências da Saúde Programa de Pós-Graduação em Ciências da Saúde, FIOCRUZ, Rio de Janeiro.

TUDESQ, André-Jean. Média et monde agricole depuis 1945. Économie rurale. $\mathrm{n}^{\circ} 184-186$, 1988. Un siècle d'histoire française agricole. pp. 205-214, p. 205.

VIANA, Hélio. História da imprensa no Brasil (1812-1869). Rio de Janeiro: Imprensa Nacional, 1945.

WELTMAN, Wanda L. A educação do Jeca: ciência, divulgação científica e agropecuária na Revista Chácaras e Quintais (1909-1948). 2008. 230f. Tese (Doutorado em História das Ciências e da Saúde). Programa de Pós-Graduação em Ciências da Saúde, FIOCRUZ, Rio de Janeiro.

ZULETA, Maria Cecília. La prensa agrícola del porfiriato como fuente para la historia económica. (Ensayo de fuentes), Signos Históricos, V. 1, p. 59-68, 1991. 